\title{
Variation of air pollution with related meteorological factors in Tripoli (case study)
}

\author{
T. A. Sharif ${ }^{1,2}$, A. K. El-Henshir ${ }^{2}$ \& M. M. Treban ${ }^{2}$ \\ ${ }^{1}$ Department of Atmospheric Science, Al-Fateh University, Tripoli, Libya \\ ${ }^{2}$ Libyan Petroleum Institute, Tripoli, Libya
}

\begin{abstract}
Ground level concentrations of nitrogen oxides $\mathrm{NO}_{x}$, ozone $\mathrm{O}_{3}$ and some meteorological variables in downtown Tripoli were measured and analyzed as a case study. It is indicated that there are strong relationships between the air pollution gases such as nitrogen oxides $\mathrm{NO}_{\mathrm{x}}$, nitrogen monoxide $\mathrm{NO}$, nitrogen dioxide $\mathrm{NO}_{2}$, in addition to ozone $\mathrm{O}_{3}$ and the meteorological factors such as wind speed and direction, solar radiation and temperature. These relationships are positive for some gases and negative for others.

Ozone and nitrogen dioxide are formed during photochemical processes by conversion of nitrogen monoxide by chain reaction, with participation of hydrocarbons and organic compound products. Low concentrations of nitrogen oxides and nitrogen monoxide were observed during the daytime while high concentrations of ozone and nitrogen dioxide were observed during the same period. In other words, these gases showed marked diurnal variation characteristics.

Pollutant emissions follow the cycles of human activity and traffic load with rapid rises near the start of each day's activities, various degrees of decrease or increase around midday, increases in early evening, and declines late at night. Such traffic load activity obviously depends on various characteristics of meteorological factors, and the meteorological factors have a significant impact on air quality.
\end{abstract}

Keywords: pollutant concentrations, meteorological factors, air pollution gases, traffic load, photochemical processes, diurnal variation. 


\section{Introduction}

Air Pollution is a problem that can only be solved by a collaboration of scientists, the public, industry and politicians. For example, educating the public in order that they might let elected officials know they are willing to pay the price for cleaning the environment is, at least partially, a role of public-interest groups; while passing laws requiring reducing emissions is a political problem. In the scientific area, the actual reduction of emissions is an engineering problem, the transport and diffusion of pollutants in the atmosphere is a meteorological problem, while transformation of atmospheric pollutants is a chemical problem.

A general characteristic of the air quality records for any one of the common pollutants in urban areas is the variability of the concentrations. Concentrations are especially variable in time: from hour to hour, day to day, season to season, and year to year. In some cases the concentrations are highly variable over rather short distances. For those pollutants that react relatively slowly while they are airborne, their temporal and spatial variations in concentration are largely due to an interaction between similar variations in atmospheric transport/diffusion and pollutant emissions. For pollutants that more readily undergo reactions in the atmosphere (e.g., photochemical oxidants $\mathrm{O}_{\mathrm{x}}$ formation or physical removal by precipitation) their concentrations also depend on the intensities of the phenomena involved (Liu et al [1]).

Temporal variations in transport/diffusion are tied to natural cycles of the weather and large spatial differences, to climatic effects (Georgii [2]). Variations in pollutant emissions are dictated by social/economic practices, and in some cases these are also influenced by the weather (Wang et al [3]; Niccum et al [4]). Although emissions, weather and atmospheric reactions may follow diurnal and seasonal cycles, their phases, amplitudes and periods are usually different (Holzworth [5]). This tends to confound explanations of observed pollutant concentrations.

\section{Site description}

The Green Square site at which the measurements were taken is located in the central area of Tripoli adjacent to the Mediterranean Sea at an elevation of $10 \mathrm{~m}$ above mean sea level. This square extends about $400 \mathrm{~m}$ in a north-south direction and $300 \mathrm{~m}$ in an east-west direction and the surface is coated with green paint. Five main streets and a subway are branched from the square, two of the streets have two-way traffic and the other four have one-way traffic, as shown in fig. 1.

\section{Data collection}

The data utilized in this case study is part of the data that was acquired with the instrumented mobile laboratory of the Technical Center for Environmental Protection positioned at The Green Square in Tripoli for a few days during May 1997. The data measured includes emission and meteorological variables. The 
primary meteorological variables measured were: wind speed, wind direction, air temperature, global solar radiation, relative humidity, atmospheric pressure and rainfall. The emission variables measured include: $\mathrm{NO}, \mathrm{NO}_{2}, \mathrm{NO}_{\mathrm{x}}, \mathrm{O}_{3}, \mathrm{SO}_{2}, \mathrm{TS}$, $\mathrm{H}_{2}$ s, THC, Non- $\mathrm{CH}_{4}, \mathrm{CH}_{4}, \mathrm{CO}$, and dust. Only the data on $21^{\text {st }}$ May 1997 will be used for illustrations and discussion.

In addition to the collection of meteorological and emission data, traffic load count was also done at the same position where the mobile laboratory was sitting. The count was taken for all streets that lead to the Green Square area for a weekday (Monday) and a weekend (Friday and Saturday).

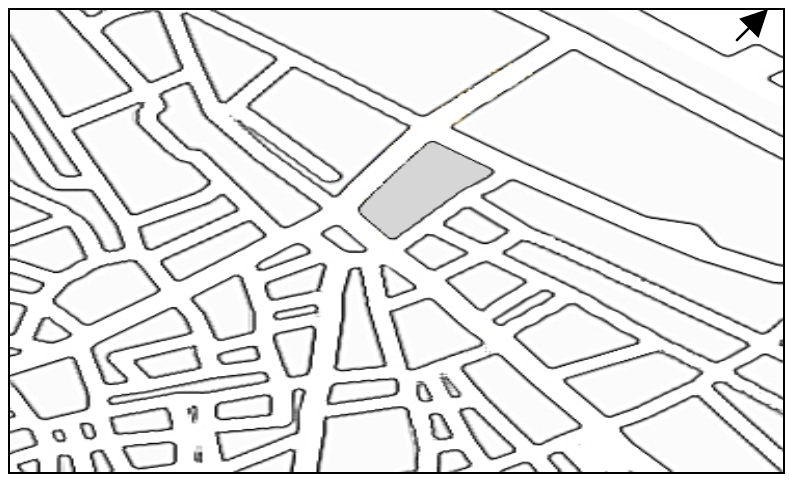

Figure 1: Downtown Tripoli.

\section{Methodology}

One of the most important objectives of the study of air pollution is the development of a methodology capable of predicting the variation of pollutant concentrations under varying meteorological and emission conditions. Such a methodology will not only enhance the present understanding of various physical and chemical processes that take place in the atmosphere, but will also provide tools for national and local air pollution agencies to use in regional and urban planning.

Many studies have attempted to develop such a methodology. They can be classified according to the basic modeling approach used: fluid, numerical or statistical.

In the fluid modeling approach, a laboratory device is employed to simulate the behavior of the atmosphere. For instance, laboratory simulation of photochemically reacting atmospheric boundary layers (Hoffert et al [6]).

In the numerical modeling approach, a set of equations is employed as a mathematical representation of the atmospheric processes. Numerical solution of this set of model equations provides the desired concentration distributions. This approach takes into account temporal as well as spatial variations in wind speed, diffusivity, mixing depth, radiation intensity and emission rate. Liu et al [1] used numerical photochemical air pollution modeling to asses the effect of atmospheric parameters on concentration levels of both primary and secondary air pollution in an urban area. 
In the statistical modeling approach, air quality data is first collected in conjunction with meteorological and emission data. This data is subsequently analyzed, and correlation relationships between air quality or emission and meteorological parameters are derived.

Statistical techniques are divided into the following three types: graphical, tabular, and summary statistics. Bornstien and Anderson [7] surveyed the statistical techniques used in validation studies of air pollution prediction models.

In this study observational data was used to graphically determine the relationship between the concentrations of gaseous pollutants such as $\mathrm{NO}_{\mathrm{x}}, \mathrm{NO}$, $\mathrm{NO}_{2}$ and $\mathrm{O}_{3}$ and meteorological parameters such as wind speed, wind direction, temperature and solar radiation. Unfortunately the use of this approach requires a large data base which is not available. Furthermore, the relationships established cannot be extracted to other locales or to future times.

Graphical presentations of the measured pollutant concentrations and meteorological variables can be carried out using values at a single site over extended time period, as in our case, or values at various sites at a single time. Variable time series plots allow us to qualitatively evaluate how they will vary with time. We can also estimate:

1) the magnitude of extreme (maximum and minimum) values,

2) the time of occurrence of extreme values,

3) stable and unstable behaviors,

4) weekdays (high source strength) and weekends (low source strength) behaviors.

\section{Results}

Graphical comparisons between emission variables and meteorological factors were carried out using values at a single site over a time period of 10 hours. The diurnal variation of each meteorological variable (wind speed, wind direction, temperature and solar radiation) was superimposed on the time series of emission variables $\left(\mathrm{NO}, \mathrm{NO}_{\mathbf{x}}, \mathrm{NO}_{2}, \mathrm{O}_{3}\right)$.

Figure 2 shows the average hourly traffic load count for all streets that branch from the Green Square figure 1. The diurnal variations shown here, especially for weekends, are generally representative. The weekday curve shows traffic peaks at noon with a lull during the morning and evening hours. Weekend curves (Friday and Saturday) differ considerably from the weekday (Monday). A significant change is also feasible between Friday and Saturday. In addition to that, curves from holiday periods may have considerable changes from the weekdays and weekends curves. It is expected that there are some relationships between the traffic load and the concentrations of the different pollutants gases, these relationships will be discussed in the subsequent paragraphs.

The main cause of the variations in gaseous pollutant concentrations is the variation in the patterns of emissions, which at least in part is related to the weather, and variations in atmospheric transport/ diffusion. However, the dearth of available emission and meteorological information precludes the 
determination of quantitative relationships. Meteorology in detailed information is required in the immediate vicinity and upwind of the air quality station and downwind of the emissions come from large specific sources. In this study, relationships of the wind speed and direction, the air temperature and solar radiation with gaseous pollutants are discussed.

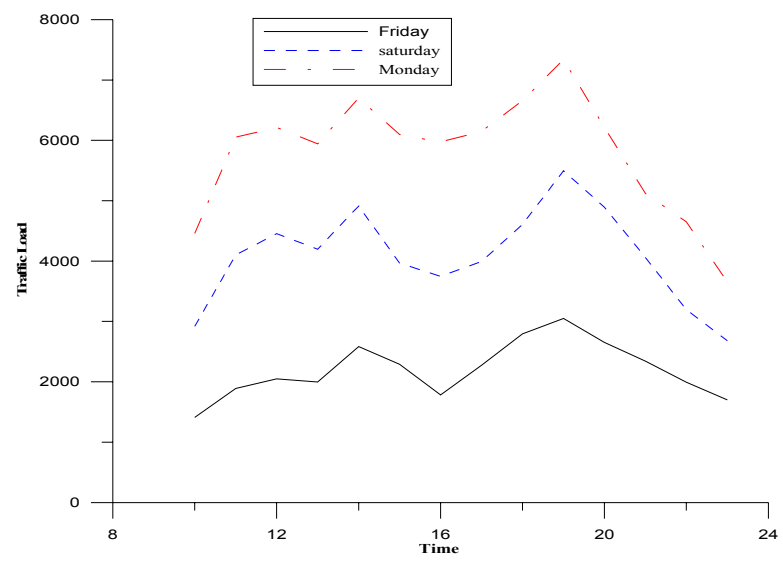

Figure 2: Hourly traffic count Green Square, Tripoli for Friday, Saturday and Monday.

Figure 3 shows the diurnal variations in concentrations of four major gaseous pollutants and wind speed on a weekday in Green Square. The variation of the wind speed with time is conversely proportional to the variation of $\mathrm{NO}$ and $\mathrm{NO}_{2}$. The wind speed is lowest during the evening while the concentrations of NO and $\mathrm{NO}_{2}$ have there lowest values during the afternoon and about midnight. The $\mathrm{NO}_{\mathrm{x}}$ is flocculating more rapidly with its higher values after the sunset and lower values at about midnight. The variation of $\mathrm{O}_{3}$ is very stable compared to $\mathrm{NO}_{\mathrm{x}}$ with larger values during afternoon.

Figure 4 shows the diurnal variations in concentrations of nitrogen monoxide, nitrogen oxides, nitrogen dioxide, ozone, and wind direction on a weekday in Green Square. The wind direction starts northeasterly in the morning and then becomes gradually southwesterly; the peak concentrations of nitrogen monoxide, nitrogen oxides and ozone are when the wind direction becomes southeasterly. As expected the nitrogen monoxide and nitrogen oxides have about a similar diurnal variation. There are no pronounced relationships between the wind direction and ozone concentration.

Figure 5 shows the diurnal variations in concentrations of nitrogen monoxide, nitrogen oxides, nitrogen dioxide, ozone and temperature on a weekday in Green square. As expected the values of temperature is high during the afternoon except when there are some clouds. As usual it states a gradual decrease after sunset to reach low values near midnight. The maximum value of temperature is in agreement with the high values of the concentrations of 


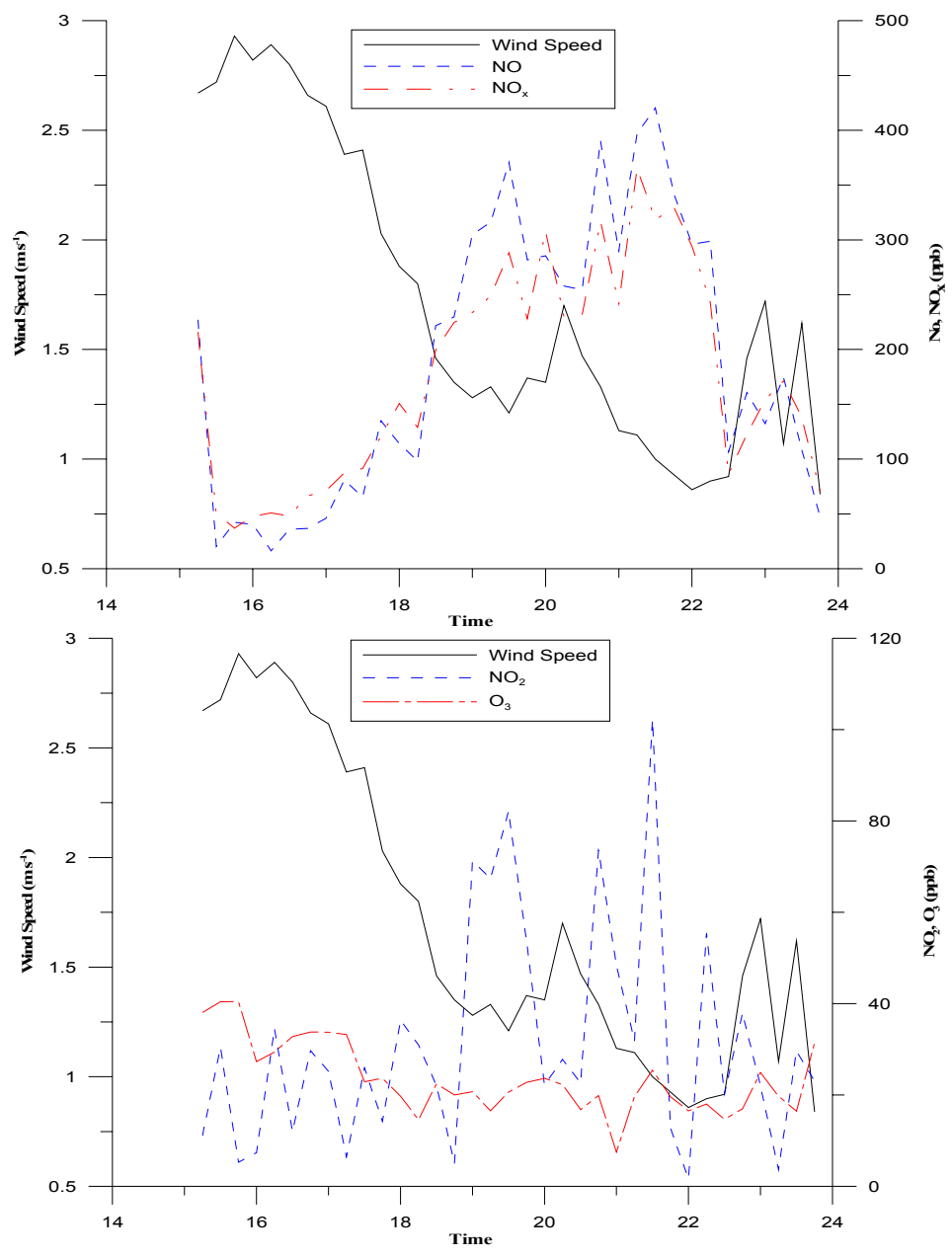

Figure 3: Diurnal variation of $\mathrm{NO}, \mathrm{NO}_{2}, \mathrm{NO}_{\mathrm{x}}$ and wind speed.

nitrogen monoxide, nitrogen oxides, and nitrogen dioxide during the afternoon period. The opposite is true for the ozone where its values are low during the same period.

Figure 6 shows the diurnal variations in concentrations of nitrogen monoxide, nitrogen oxides, nitrogen dioxide, ozone and solar radiation on a weekday in Green Square. The solar radiation is a maximum at about 3:30pm then decreases gradually to become a minimum at sunset. The ozone values are high during the period where solar radiation values are high. These high values of ozone concentration are due to photochemical processes.

As seen from figures 3-6 each meteorological factor has a different characteristic of diurnal variation. The behaviors of the concentration curves have a meaningful variation in relation to the specific meteorological factor. 


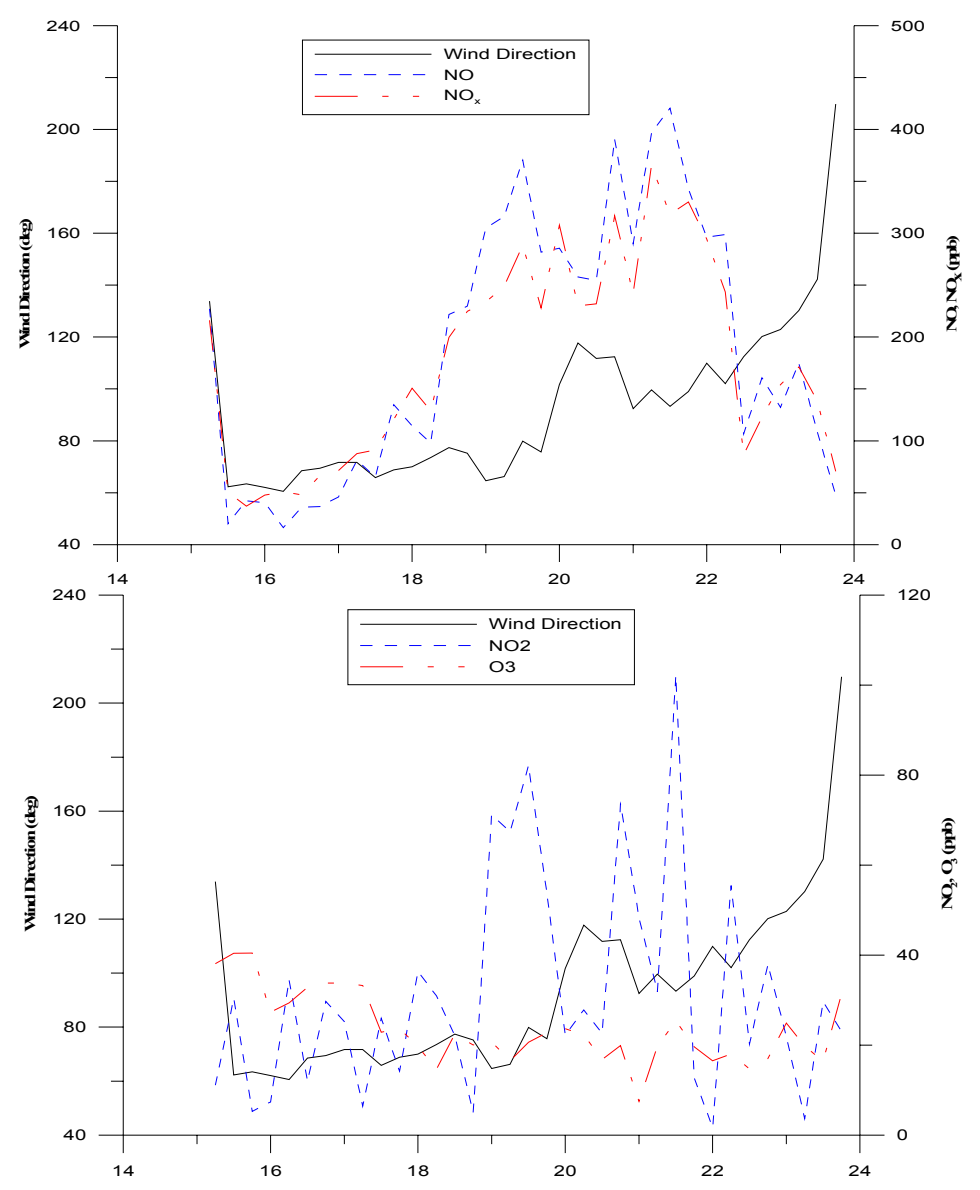

Figure 4: Diurnal ariation of $\mathrm{NO}, \mathrm{NO}_{2}, \mathrm{NO}_{\mathrm{x}}$ and wind direction.

\section{Conclusion}

In this paper we have used the technique that has been used by many meteorologists to find the relationship between the meteorological factors' variations with pollutant concentrations. The case study was for a week day over a period of 9 hours. A similar case study can extend to cover the weekend for a single station and/or area sources.

Graphical summaries were used to demonstrate qualitatively how the air pollution concentrations and meteorological variables vary over time for a single station. The relationships of the measured concentrations of the pollutant gases are realistic; the wind speed is a good example. Whenever the wind speed values are high, the concentration values are low. 

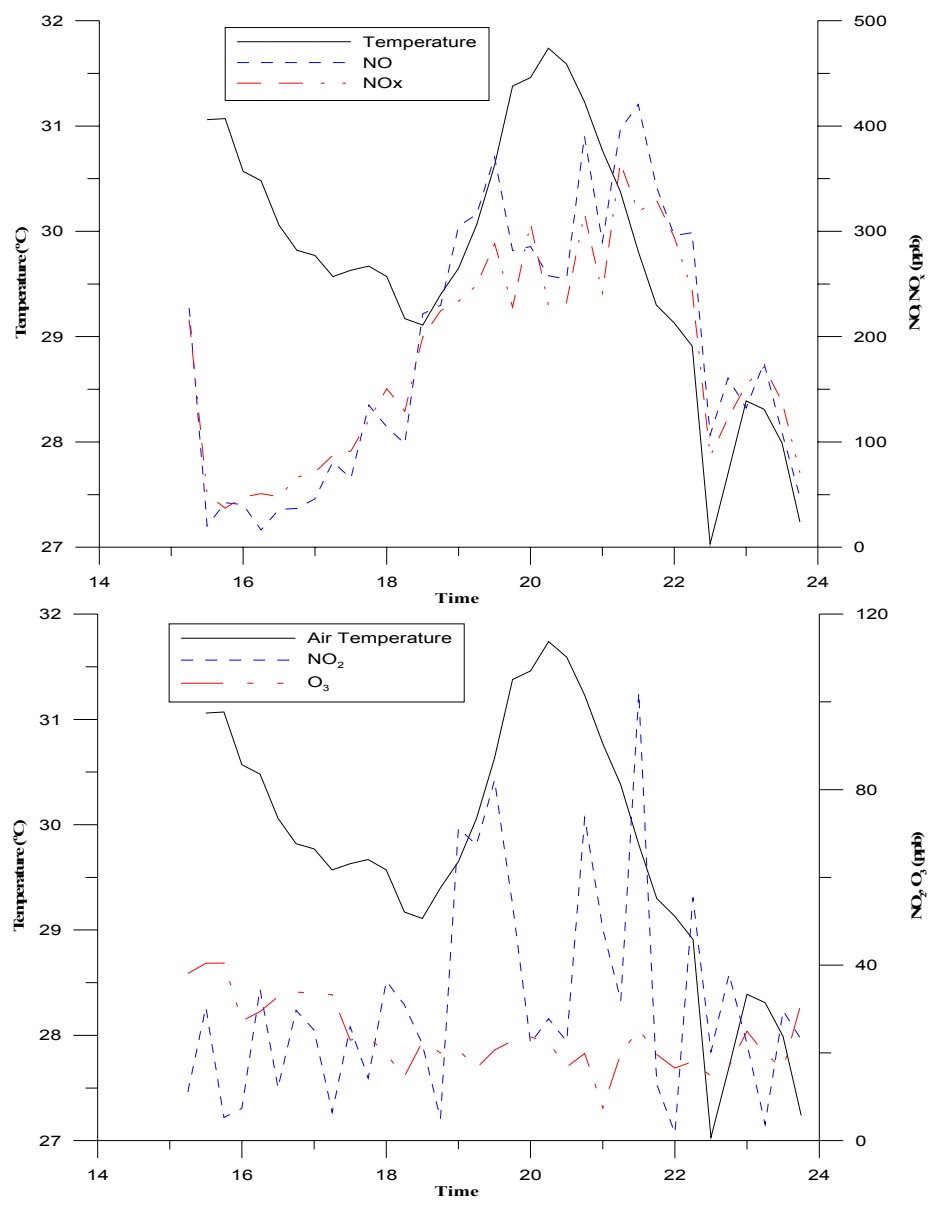

Figure 5: Diurnal variation of $\mathrm{NO}, \mathrm{NO}_{2}, \mathrm{NO}_{\mathrm{x}}$ and temperature.

Very generally, pollutant emissions follow the cycles of human activity and load traffic with rapid rises near the start of each day's activities, various degrees of decrease or increase around mid-day, increases in early evening, and decline late at night. Such traffic load activity obviously depends on various characteristics of meteorological factors. And the meteorological factors have a significant impact on air quality.

The overall effect on air quality of the usual diurnal patterns of emission and dilution is the high concentrations at the beginning of a day's activities are mainly due to a morning surge in emissions; lower concentrations in the forenoon and afternoon are due to increased dilution and sometimes partly to decreased emissions; by both decreasing dilution and increasing emissions; and low concentrations at night are mainly due to less emissions. Ozone which depends on solar radiation for its formation in the atmosphere, is of course an exception. 

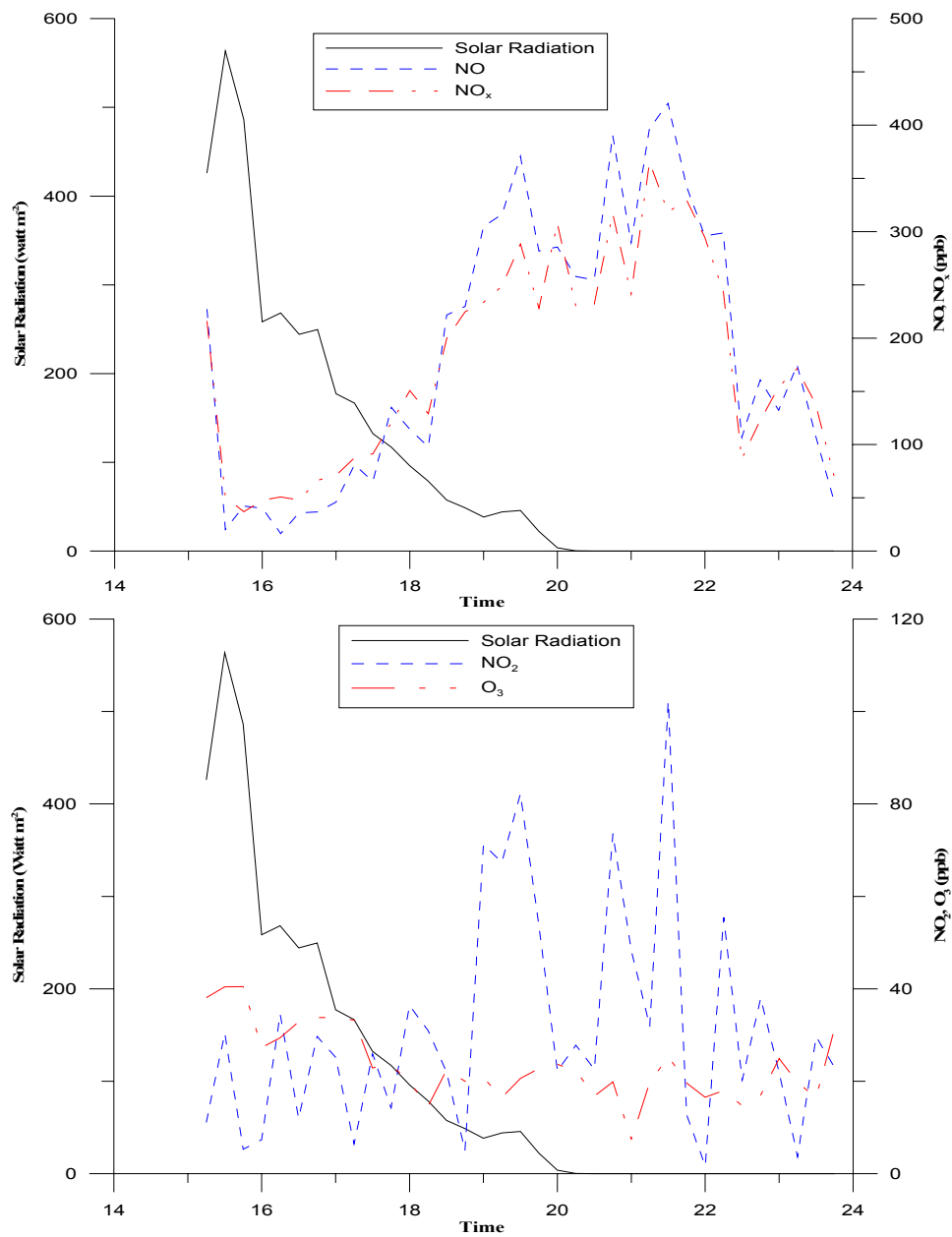

Figure 6: Diurnal variation of $\mathrm{NO}, \mathrm{NO}_{2}, \mathrm{NO}_{\mathrm{x}}$ and solar radiation.

\section{Acknowledgements}

We would like to express our deep thanks to the Technical center for Environmental Protection for supplying the emission data and the Libyan Petroleum Institute for supporting part of this work.

\section{References}

[1] Liu, M.K., Whitney, C. \& Roth, P.M., Effects of atmospheric parameters on the concentration of photochemical air pollution. J. Appl. Meteo., 15(8), pp. 829-835, 1976. 
[2] Georgii, H.W., The effects of air pollution on urbane climates. Bull. World Health Org., 40, pp. 624-635, 1969.

[3] Wang, X..J., Zhang, W., Li Y., Yang K.Z. \& Bai, M., Air quality improvement estimation and assessment using contingent valuation method, a case study in Beijing. Environmental Monitoring and Assessment, 111(13), pp. 89-112, 2006.

[4] Niccum, E.M., Lehrman, D.E. \& Knuth, W.R., The influence of meteorology on the air quality in the San Luis Obispo Country-southern western San Joaquin Valley region for 3-6 August 1992. J. Appl. Meteo., 34(8), pp. 1834-1847, 1995.

[5] Holzworth, G.C., Variations of meteorology, pollutant emissions and air quality. Second Joint Conference on Sensing of Environment Pollutants: Washington D.C., December 10-12, pp. 247-255, 1973.

[6] Hoffert, M. I., Hoydysk, W. G., Hameed, S. \& Lebedeff, S. A., Laboratory simulation of photochemically reacting atmospheric boundary layers: a feasibility study. Atmos. Environ., 9, pp. 33-48, 1975.

[7] Bornstein, R.D. \& Anderson, S.F., A Survey of statistical Techniques used in Validation Studies of Air Pollution Prediction Models, Technical Report No. 23, Stanford University, pp. 1-47, 1979. 